\title{
Caracterização do perfil de produção e qualidade fisiológica de sementes orgânicas do algodão Gossypium hirsutum L. em Remígio, Estado da Paraíba, Nordeste do Brasil
}

\section{Josenildo Costa Silva ${ }^{1}$, Marcos Barros de Medeiros ${ }^{1}$, Virgínia Maria Magliano Morais ${ }^{2}$, Hélder Formiga Fernandes ${ }^{3}$, Elizandra Ribeiro de Lima Pereira4, Edna de Oliveira Silva ${ }^{5}$ Fabiana Xavier $\operatorname{Costa}^{6}$ e Aline Costa Ferreira $^{7}$}

\footnotetext{
${ }^{1}$ Universidade Federal da Paraíba. Centro de Ciências Humanas Sociais e Agrárias. Departamento de Agricultura. Campus III. Bananeiras-PB, Brasil (CEP 58220-000). E-mail: josenildostr@gmail.com.

${ }^{2}$ Universidade Federal da Paraíba. Centro de Educação. Departamento de Fundamentação da Educação. Campus I. João Pessoa-PB, Brasil (CEP 58051-900).

${ }^{3}$ Universidade Federal da Paraíba. Centro de Ciências Exatas e da Natureza. Programa de Pós-Graduação em Desenvolvimento e Meio Ambiente. Campus I. João Pessoa-PB, Brasil (CEP 58051-900).

${ }^{4}$ Universidade Federal da Paraíba. Programa de Pós-Graduação em Biotecnologia (RENORBIO). Campus I. João Pessoa-PB, Brasil (CEP 58051-900).

5Universidade Federal da Paraíba. Centro de Ciências Agrárias. Programa de PósGraduação em Agronomia. Campus II. Areia-PB, Brasil (CEP 58397-000).

6Universidade Federal de Campina Grande. Centro Tecnologia e Recursos Naturais. Programa de Pós-Graduação em Engenharia e Recursos Naturais. Campina GrandePB, Brasil (CEP 58400-000).

${ }^{7}$ Universidade Federal de Campina Grande. Centro de Ciências e Tecnologia Agroalimentar. Campina Grande-PB, Brasil (CEP 58840-000).
}

Resumo. A produção agroecológica de culturas de subsistência em comunidades rurais se destaca como a principal fonte de renda das famílias, além de ser uma forma de produção $23 / 12 / 2019$ sustentável, não agredindo o meio ambiente. Objetivou-se com essa pesquisa identificar o perfil de produção no Assentamento Queimadas no Município de Remígio, Região Semiárida do Estado da Paraíba, Nordeste do Brasil, através de visitas, palestras e verificar por meio de testes em laboratório a qualidade fisiológica de sementes de algodão branco e marrom oriundas de manejo orgânico de dois lotes distintos. Inicialmente realizou-se uma caracterização do perfil de produção no Assentamento por meio de visitas e palestras com os principais produtores de algodão da Associação comunitária do Assentamento Queimadas. Posteriormente, foram realizadas as análises de qualidade fisiológica das sementes. Para emergência das plântulas foram

Aceito

28/07/2020

Disponível on line

$31 / 07 / 2020$

Publicado

$31 / 08 / 2020$

Acesso aberto

ISSN 2359-1412/RBGAS-2019-0113/2020/7/16/20/739

Rev. Bras. Gest. Amb. Sustent.

http://revista.ecogestaobrasil.net 
utilizadas quatro amostras de 50 sementes no substrato areia. Foi realizado o comprimento das plântulas com utilização de régua graduada em milímetro, medindo-se as plântulas inteiras, seguidamente foram colocadas em sacos de papel e levadas para secar em estufa até obtenção de massa constante. 0 delineamento estatístico empregado foi o DIC (Delineamento inteiramente casualizado) em modelo fatorial $2 \times 2$ (dois tipos de algodão orgânico, branco e marrom x 2 lotes diferentes). Portanto, o perfil da produção orgânica de algodão em Remígio-PB destaca a agricultura familiar de subsistência, a diversificação de culturas e a sustentabilidade. Com relação à qualidade fisiológica, comprovou-se que as sementes de algodão marrom são menos vigorosas do que as sementes de algodão branco em emergência e vigor, demonstrado em todas as variáveis estudadas: emergência, comprimento e massa seca das plântulas.

Palavras-chave: Agricultura familiar; Sustentabilidade; Agroecologia.

\begin{abstract}
Characterization of the production profile and physiological quality of organic cotton seeds Gossypium hirsutum L. in Remígio, Paraíba State, Northeast Brazil. Agroecological production of subsistence crops in rural communities stands out as the main source of household income, in addition to being a form of sustainable production, not harming the environment. The objective of this research was to identify the production profile in the Queimadas Settlement in Municipality, Semiarid Region of Paraíba State, Northeast Brazil, through visits, lectures and to verify by means of laboratory tests the physiological quality of white and brown cotton seeds from organic management of two different lots. Initially a characterization of the production profile in the Settlement was carried out through visits and lectures with the main cotton producers of the Community Association of the Queimadas Settlement. Subsequently, physiological seed quality analysis were performed. For seedling emergence, four samples of 50 seeds were used in the sand substrate. The length of the seedlings was made using a millimeter-graded ruler, measuring the whole seedlings, then they were placed in paper bags and taken to dry in an oven until a constant mass was obtained. The statistical design used was the DIC (completely randomized design) in a $2 \times 2$ factorial model (two types of organic cotton: white and brown $\mathrm{x} 2$ different lots). Therefore, the profile of organic cotton production in Remígio highlights family subsistence agriculture, crop diversification and sustainability. Regarding physiological quality, it was proved that brown cotton seeds are inferior to white cotton seeds in emergence and vigor, demonstrated in all variables studied: emergence, length and dry mass of seedlings.
\end{abstract}

Keywords: Family farming; Sustainability; Agroecology.

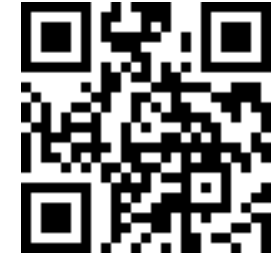

ORCID

(1) 0000-0002-9966-5955 Josenildo Costa Silva

(1) 0000-0002-1633-3227

Marcos Barros de

Medeiros

D 0000-0001-8083-1979

Virgínia Maria Magliano Morais

D) 0000-0002-0370-0673

Hélder Formiga

Fernandes

(D) 0000-0003-3191-182X

Elizandra Ribeiro de

Lima Pereira

(D) 0000-0001-5633-3152

Edna de Oliveira Silva

(ㄷ) 0000-00002-6396-8305

Fabiana Xavier Costa

(D) 0000-0002-5518-1924

Aline Costa Ferreira 


\section{Introdução}

A produção agroecológica de culturas de subsistência em comunidades rurais se destaca como a principal fonte de renda das famílias, além de ser uma forma de produção sustentável, não agredindo o meio ambiente. Uma das culturas promissoras no agreste paraibano é o algodão Gossypium hirsutum L.

O algodoeiro, planta da Família Malvaceae é cultivado, no Brasil, em três macrorregiões, a Norte-Nordeste (Tocantins, Maranhão, Piauí, Ceará, Rio Grande do Norte, Paraíba, Pernambuco, Alagoas e Bahia), a Centro-Oeste (Mato Grosso, Mato Grosso do Sul e Goiás) e a Sul-Sudeste (São Paulo, Paraná e Minas Gerais). Em todas elas encontram-se diferentes sistemas de produção, desde pequenas glebas, de agricultura familiar, até culturas empresariais, de alto nível tecnológico (Fuzatto et al., 2014).

Com a colaboração de sindicatos, secretaria de agricultura e organizações não governamentais (ONGs) cada vez mais atuantes no setor agrícola, percebe-se um novo olhar para a história de vida de várias famílias agricultoras. A Paraíba é o Estado onde mais se planta e colhe algodão naturalmente colorido no Brasil, e onde também acontecem pesquisas importantes para se obter a pluma de algodão naturalmente colorido que tenha fibras mais compridas e mais resistentes.

0 algodão colorido foi desenvolvido pelos incas e astecas há 4.500 anos, bem como por outros povos antigos das Américas, Ásia, África e Austrália. Esses algodões coloridos, sempre foram considerados como misturas indesejáveis pelos industriais, tendo uso apenas artesanal ou ornamental, principalmente nos Estados da Bahia e Minas Gerais. Alguns algodoeiros coloridos foram preservados em bancos de germoplasma da EMBRAPA Algodão, em Patos, $\mathrm{PB}$, desde 1984. A partir de 1989, foi iniciado o trabalho de melhoramento genético (Fernandes et al., 2004).

A adaptabilidade das cultivares BRS 200 Marrom e BRS Verde às condições de semiárido do Nordeste brasileiro deve ser explorada principalmente para pequenos produtores organizados em associações cooperativas que, a partir de ações ordenadas e em conjunto, podem galgar novos patamares na escala da competitividade a partir da aquisição de conhecimentos e tecnologias concebidas pela Embrapa Algodão, específicos para a realidade em questão (EMBRAPA, 2002). As variedades naturalmente coloridas pesquisadas pela Embrapa dispensam o uso de corantes químicos, por isso não poluem o meio ambiente e ainda representam uma economia de cerca de $70 \%$ de água no processo de acabamento do tecido. Em geral, o algodão colorido também é produzido de forma orgânica, sem o uso de insumos e fertilizantes químicos (Moura et al., 2014).

No caso particular do cenário agrícola da cultura do algodão em nossa região, destaca-se a atuação da EMBRAPA Algodão, instituição que tem desenvolvido pesquisas de qualidade na área agrícola; a qual por meio de parcerias distribui sementes de algodão para famílias assentadas do Município de Remígio, no semiárido do Estado da Paraíba. Por meio dessa iniciativa juntamente com o sindicato dos trabalhadores rurais e a ONG Arribaçã têm garantido a obtenção de sementes de qualidade no próprio assentamento para futuros plantios.

A Embrapa já lançou seis variedades de algodão colorido em tonalidades que vão do verde-claro aos marrons claro, escuro e avermelhado. São elas: BRS 200 Marrom, BRS Rubi, BRS Topázio, BRS Safira e BRS Jade. Por essa razão, empresas lançaram em 2019 o jeans produzido com algodão colorido produzido pela EMBRAPA na Paraíba. Por dispensar o processo de tingimento, o novo jeans usa menos água no processo de fabricação (Globo, 2019). 0 mercado para o algodão colorido ainda é restrito, sendo o produto comercializado para pessoas alérgicas a corantes sintéticos, grupos ambientalistas e ONGs que desenvolvem trabalhos com agricultura orgânica (Freire, 2018). 
Entre os eventos que oferecem espaço para exposição e comercialização de produtos feitos com algodão naturalmente colorido no Estado destaca-se o Salão de Artesanato da Paraíba, um evento que ocorre duas vezes ao ano: no verão, em João Pessoa e no mês de junho, em Campina Grande. A realização é do Governo do Estado da Paraíba, por meio do Programa do Artesanato da Paraíba, vinculado à Secretaria de Estado do Turismo e Desenvolvimento Econômico, dentre outras parcerias.

As pesquisas da Embrapa Algodão em cima da tecnologia algodão naturalmente colorido buscam ainda uma maior produtividade e maior rendimento de pluma, após o descaroçamento. As cultivares de algodão diferenciam-se quanto ao tamanho da fibra (curto, médio, longo), duração de ciclo (curto: 120 a 140 dias; longo: 150 a 180 dias), porte baixo ou alto, resistência a doenças, entre outras características. 0 produtor busca então adequar as características ao mercado e as condições ambientais que lhe favorecem, para tanto é importante à utilização de sementes com elevada qualidade (Cocco, 2012). 0 conhecimento da qualidade fisiológica de sementes é essencial para um adequado manejo e obtenção de maiores produtividades.

A qualidade das sementes é um parâmetro importante que deve ser visto no processo produtivo de qualquer cultura, pois sucesso de uma lavoura em geral, também está atrelado ao uso de sementes de boa qualidade (Carvalho e Nakagawa, 2012). 0 uso de sementes, de alta qualidade e desempenho, é amplamente reconhecido pelos agricultores familiares como um dos meios mais efetivos de minimizar custos e riscos. 0 aumento do desempenho das sementes se dá através de tratamentos especiais, como o beneficiamento e os procedimentos para melhorar as condições de semeadura.

Essa pesquisa foi realizada no sentido de enfocar a importância da produção de algodão no assentamento Queimadas buscando um novo olhar para a história de vida das famílias agricultoras. Dessa forma, a aplicabilidade do trabalho envolve tanto a questão da valorização social e econômica bem como a identificação da qualidade das sementes para futuros plantios.

Objetivou-se com a pesquisa identificar o perfil de produção no assentamento Queimadas, localizado no Município de Remígio, Região Semiárido do Estado da Paraíba, por meio de visitas, palestras e verificar por meio de testes de laboratório a qualidade fisiológica de sementes de algodão branco e marrom oriundas de manejo orgânico de dois lotes distintos.

\section{Material e métodos}

\section{Local}

A pesquisa foi desenvolvida no Assentamento Queimadas, localizado no Município de Remígio, no semiárido do Estado da Paraíba, em parceria com o Laboratório de Análise de Sementes, do Centro de Ciências Agrárias, da Universidade Federal da Paraíba.

\section{Caracterização do perfil de produção no assentamento queimadas}

Inicialmente realizou-se uma caracterização do perfil de produção no Assentamento por meio de visitas e palestras com os principais produtores de algodão da Associação comunitária do Assentamento Queimadas, em Remígio. Por meio de conversas e visitas nas áreas de produção procurou-se identificar as dificuldades e perspectivas de produção e suas experiências, nesse sentido, alguns agricultores foram muito prestativos, facilitando, assim o desenvolvimento da pesquisa. Caracterizaram a produção de forma clara e objetiva, relatando como foi a iniciativa, as dificuldades e desafios enfrentados, bem como a persistência que levou ao destaque na cadeia de produção do algodão orgânico na Paraíba. 


\section{Aquisição e origem das sementes}

As sementes utilizadas foram provenientes do banco de sementes comunitário do Assentamento Queimadas (Remígio-PB) originárias da produção local.

Foram utilizadas sementes de algodão branco e sementes de algodão marrom de dois lotes de algodão orgânico obtidos da produção dos agricultores (sementes recémcolhidas) e Lote 2 (armazenadas por 12 meses).

A qualidade fisiológica das sementes foi desenvolvida no Laboratório de Análise de Sementes da Universidade Federal da Paraíba (CCA/UFPB-Areia-PB).

\section{Qualidade fisiológica das sementes}

Para avaliar a qualidade inicial dos lotes foi verificado o teor de água das sementes expresso em porcentagem, sendo determinado pelo método da estufa a $105{ }^{\circ} \mathrm{C} \pm 3{ }^{\circ} \mathrm{C}$ durante $24 \mathrm{~h}$, utilizando-se duas subamostras de $50 \mathrm{~g}$ para cada repetição e calculado, de acordo com as Regras para Análise de Sementes - RAS (Brasil, 2009).

Para emergência das plântulas foram utilizadas quatro amostras de 50 sementes, sendo semeadas no substrato areia lavada e esterilizada em bandejas plásticas (dimensões: $49 \mathrm{~cm} \times 37 \mathrm{~cm} \times 7 \mathrm{~cm}$ ), as quais foram colocadas em bancada de alvenaria em ambiente telado protegido sem controle de temperatura e umidade, com regas diárias para manter o substrato úmido.

A avaliação baseou-se na contagem de plântulas emersas a um centímetro do solo e realizadas após o sétimo dia de plantio, com contagens de 2 em 2 dias até a estabilização do estande, o qual ocorreu no $12^{\circ}$ dia. 0 comprimento das plântulas foi realizado através da utilização de régua graduada em milímetro $(\mathrm{mm})$, medindo-se as plântulas inteiras, seguidamente as plântulas foram colocadas em sacos de papel e levadas para secar em estufa até obtenção de massa constante das amostras.

\section{Delineamento estatístico utilizado}

0 delineamento estatístico empregado foi o DIC (delineamento inteiramente casualizado) em modelo fatorial $2 \times 2$ (dois tipos de algodão orgânico: branco e BRS 200 Marrom x 2 Lotes distintos; Lote 1: sementes recém colhidas e Lote 2: sementes armazenadas por 12 meses) com 4 repetições de 50 sementes. Para o processamento dos dados utilizou-se o programa ASSISTAT.

\section{Resultados e discussão}

\section{Perfil de produção e perspectivas}

A produção de algodão teve início e expansão com o senhor José de Sinésio (Zé de Sinésio; assim conhecido por todos da comunidade), o qual começou a produzir o algodão com muitas dificuldades e desafios, enquanto os demais agricultores desistiram do algodão por não obterem resultados satisfatórios, ele, porém insistiu em observações em campo, observando o clima e as pragas, não desistiu e insistiu no plantio juntamente com as demais culturas de subsistência.

As pragas dificultaram bastante à adaptação do algodão nas áreas de plantio e fazendo suas observações acerca das pragas principalmente o bicudo, resolveu fazer diferente, plantar já no meio do período chuvoso, dando um espaçamento maior entre as plantas. Assim, o algodão iniciaria a fase produtiva no final das chuvas e o crescimento já seria na fase de estiagem.

A construção do projeto Rede Paraíba de Algodão Agroecológico começou em 2008 com a participação da comunidade de três assentamentos rurais em parcerias com sindicatos rurais de Remígio, Casserengue e Solânea, bem como o Pólo Sindical, EMBRAPA e empresas compradoras de algodão como a COOPNATURAL e COEXIS. 
Observou-se a importância do projeto Escola Participativa do Algodão, o qual favoreceu a formação dos agricultores com visitas de intercâmbio, seminários regionais, "dias de campo", transição agroecológica e a formação da Rede Paraíba de Algodão Agroecológico, contribuindo na validação de forma participativa das práticas agroecológicas, garantindo a sustentabilidade local e a geração de renda para as famílias e conseguiram se destacar por ser o primeiro Assentamento rural que certificou o primeiro algodão orgânico da Paraíba.

A compreensão das concepções de desenvolvimento pensadas pela Rede Paraíba de Algodão Agroecológico, se fez importante para a pesquisa, pois elas orientam sobre as forma de acesso a políticas públicas, ampliação de mercados e articulação de parcerias (Almeida, 2011).

A experiência foi favorável e se expandiu e outras pessoas passaram a fazer parte dela. A iniciativa chamou a atenção da EMBRAPA Algodão, que estimulou os agricultores do assentamento a produzir para comercialização e forneceram também sementes de algodão colorido para experimentação e cultivo.

Com a expansão da rede de produção do algodão no Assentamento conseguiram obter êxito e atualmente cada agricultor é certificado como produtor orgânico. A RBA: Rede Borborema de Agroecologia que é o Organismo Participativo de Aceitação e Conformidade (OPAC), criado para certificar a produção agroecológica e garantir a comercialização do produto, conta atualmente com 34 agricultores familiares certificados e cinco grupos de produção. Eles começaram o manejo do algodão agroecológico em 2006, através do apoio técnico da ONG Arribaçã.

Com o acompanhamento e assistência técnica da organização Arribaçã, eles deram início ao projeto Escola Participativa do Algodão e, tempos depois, fundaram a Associação Comunitária do Assentamento Queimadas que até os dias atuais continuam trabalhando com algodão e as demais culturas. A produção de algodão é uma forma de diversificar os cultivos e melhorar a renda das famílias do Assentamento Queimadas.

0 processo de formação dos agricultores familiares é uma ferramenta para o desenrolar do processo de produção do algodão orgânico. Neste sentido, Almeida (2011) justifica que:

\footnotetext{
0 processo de formação passa por alguns segmentos perpassando também por algumas ações como: acompanhamento Técnico das áreas de produção, certificação orgânica, convivência com pragas do Algodoeiro, colheita, beneficiamento, produção de sementes e transição agroecológica. Para o processo de formação foram utilizadas pelo projeto algumas ferramentas para a formação dos agricultores familiares norteadas por meio de metodologias participativas: visitas de intercâmbios, dias de campo, seminário regional sobre o algodão e transição agroecológica.
}

Diante da presente caracterização do perfil produtivo local, observou-se nas áreas de plantio diversos tipos de consórcios, utilização de compostagem, adubos orgânicos e técnicas de rotação de culturas. Constatou-se que as famílias agricultoras têm mantido os seus sistemas de produção agrícola de forma diversificada por meio de consórcios de culturas, com base na produção de alimentos para o consumo, reservando para a venda 0 excedente, comercializando os produtos no comércio local e feiras livres.

\section{Avaliação da qualidade fisiológica das sementes de algodão}

No início dos testes as sementes de algodão marrom e branco tinham $11 \%$ e $12 \%$ de umidade respectivamente. De acordo com a Figura 1, verifica-se que houve diferença significativa com relação à emergência das cultivares de algodão branco e marrom, observando-se que a emergência das plântulas do algodão marrom foram inferiores as do algodão branco tanto no Lote 1 quanto no Lote 2. Observa-se também que não houve 
diferenças com relação a emergência de sementes recém colhidas (Lote 1) e sementes armazenadas por 12 meses (Lote 2).

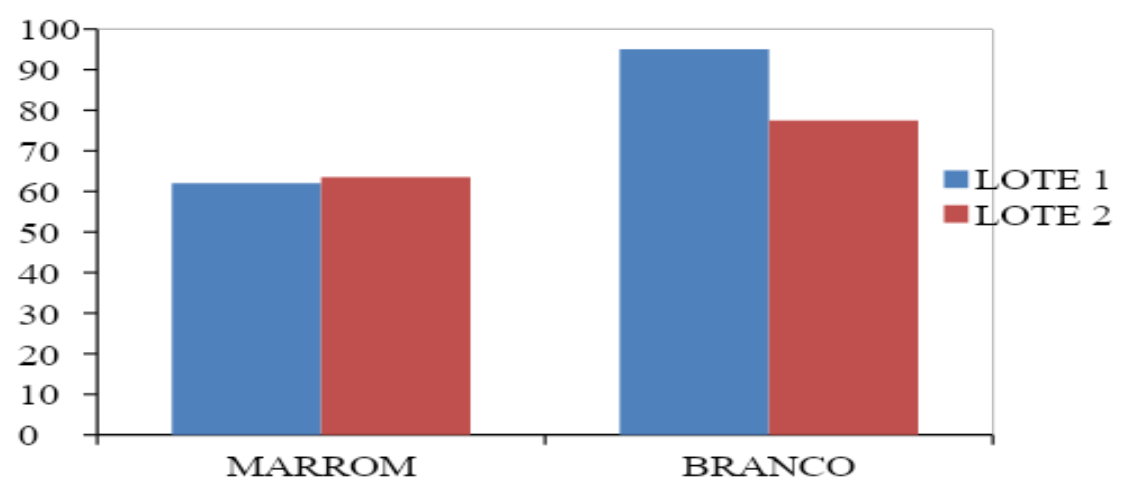

Figura 1. Emergência de plântulas de algodoeiro marrom e branco.

Conforme Oliveira et al. (2010) a redução no vigor de sementes de algodão é diferenciado quanto a cultivar. 0 vigor das sementes pode influenciar a emergência, 0 desempenho e produtividade das plantas, dependendo de cada espécie e de fatores ambientais. Segundo Marcos Filho (2005) a utilização de sementes de boa qualidade fisiológica é fator primordial no estabelecimento de qualquer lavoura. Neste sentido, Chagas et al., 2018 também informa que a qualidade fisiológica das sementes é um fator crucial no processo de produção, definindo o rendimento potencial dos cultivos.

Um dos fatores limitantes para o sucesso da cultura do algodoeiro tem sido a dificuldade de obter sementes com qualidade física, fisiológica e sanitária capazes de proporcionar o estabelecimento dessa cultura com população ideal e com plântulas uniformes e vigorosas, com respostas diretas no aumento da produção por área plantada (Nunes et al., 2015).

Com relação ao vigor demonstrado através do comprimento e da massa seca de plântulas (Tabela 1), observa-se para comprimento de plântulas que houve diferença entre os lotes, sendo as plântulas do Lote 1 de tamanho inferior as do Lote 2 para o algodão marrom, já as plântulas provenientes das sementes do algodão branco apresentaram tamanhos estatisticamente iguais em ambos os lotes. Em relação à massa seca observa-se que o Lote 1 (sementes recém-colhidas) é menos vigoroso que o Lote 2 (sementes armazenadas). Segundo Queiroga et al. (2009), algumas espécies de algodão colorido aumenta o seu vigor quando as sementes são armazenadas por mais tempo.

Tabela 1. Comprimento e massa seca de plântulas de algodoeiro marrom e branco.

\begin{tabular}{|c|c|c|}
\hline \multirow{2}{*}{ Lotes } & \multicolumn{2}{|c|}{ Comprimento (cm) } \\
\cline { 2 - 3 } & BRS 200 Marrom & Branco \\
\hline Lote 1 & $23,95 \mathrm{bA}$ & $25,85 \mathrm{Aa}$ \\
\hline Lote 2 & $27,06 \mathrm{aA}$ & Bassa seca (mg) \\
\hline & \multicolumn{2}{c|}{ Branco } \\
\hline & BRS 200 Marrom & $0,24 \mathrm{aA}$ \\
\hline Lote 1 & $0,13 \mathrm{bA}$ & $0,11 \mathrm{bA}$ \\
\hline Lote 2 & $0,21 \mathrm{aB}$ & \multicolumn{2}{c|}{ Ma } \\
\hline
\end{tabular}

Médias seguidas de mesma letra minúscula na coluna e maiúscula na linha não diferem entre si pelo teste de Tukey a 5\% de probabilidade. 
Observou-se no algodão branco que o lote 2 é menos vigoroso com relação à massa seca de plântulas. Uma questão relevante para esse resultado foi a presença de fungos do gênero Aspergillus spp. em algumas sementes e em algumas plântulas emergidas. A presença de fungos como o Aspergillus spp. em algumas sementes armazenadas pode ser um fator considerável nesse resultado. Sementes de algodoeiro, independente do beneficiamento empregado, são susceptíveis à contaminação por fungos de armazenamento, principalmente os do gênero Aspergillus (Lopes et al., 2006).

Desta forma, Moraes (2006) afirma que o atraso ou diminuição na velocidade do processo de germinação aumenta a suscetibilidade das sementes a ataques de microrganismos presentes no solo, reduzindo assim, a emergência de plântulas e, como consequência, comprometendo o estande final da lavoura. Sendo assim, uma germinação rápida e uniforme é de suma importância, uma vez que nas regiões do semiárido os recursos hídricos são bastante escassos (Nunes et al., 2015).

De acordo com as observações feitas na presente pesquisa, pode-se constatar que as sementes de algodão marrom apresentam vigor inferior às sementes de algodão branco, provavelmente devido a sua própria constituição genética e a adaptação ao ambiente e até mesmo as condições de armazenamento podem afetar a qualidade das sementes, pois as sementes recém-colhidas de algodão marrom (Lote 1 ) tiveram um vigor menor representado pelo comprimento e massa seca das plântulas do que as do lote armazenado (Lote 2). Para Thomazini (2011) o vigor das sementes é um conjunto de características que determinam o potencial para emergência rápida e uniforme de plântulas normais, sob ampla diversidade de condições de ambiente. Segundo Marcos Filho (2005) a utilização de sementes de boa qualidade fisiológica é fator primordial no estabelecimento de qualquer lavoura.

Desta forma, Brunetta et al. (2007) afirma que a qualidade das sementes de algodão pode ser influenciada por diversos fatores, que podem ocorrer no campo, antes e durante a colheita e por outras intempéries que podem ocorrer no período pós-colheita, podendo se estender pelas etapas subseqüentes de produção, como o beneficiamento, o deslintamento e o armazenamento. 0 emprego de testes que viabilizam a classificação dos lotes em diferentes níveis de vigor representa um subsídio importante para tomada de decisões para empresas de pesquisas e comercialização de sementes, direcionando-os para locais em que poderiam apresentar maior potencial de desempenho (Nunes, 2018).

Portanto, com os dados obtidos e a discussão proposta pode-se afirmar que as sementes de algodão marrom dependem de uma série de fatores para expressarem o vigor, tais como fatores ambientais, armazenamento e as características genéticas herdadas. Segundo Freire (2018) os avanços obtidos até então com o algodão colorido decorreram da exploração do germoplasma natural do algodão, por meio de métodos tradicionais de melhoramento genético. 0 uso da biotecnologia de transferência de genes que controlam a expressão de várias tonalidades de cores, das espécies selvagens de algodão para as cultivares modernas, já constitui um dos objetivos das empresas de biotecnologia que trabalham com algodão, no mundo, o que pode resultar em avanços tecnológicos e em economia de tempo e recursos na obtenção das futuras cultivares de algodão colorido e melhoria dos genótipos das sementes.

\section{Conclusões}

Portanto, o perfil da produção orgânica de algodão em Remígio-PB destaca a agricultura familiar de subsistência, a diversificação de culturas, a sustentabilidade com as práticas agroecológicas, agregação de valor do produto local, fortalecimento de vínculos com agricultores, instituições de pesquisas e empresas parceiras.

A produção de algodão orgânico é importante tanto para o Assentamento queimadas como para toda a rede de produção de algodão orgânico, onde ocorre 
valorização das experiências dos agricultores familiares por meio de pesquisas participativas a partir da realidade local.

Com relação à qualidade fisiológica dos lotes de algodão, os testes demonstraram que as sementes de algodão marrom são menos vigorosas do que as sementes de algodão branco, demonstrado em todas as variáveis estudadas.

Espera-se como perspectivas futuras, ao longo dos plantios, com novas sementes difundidas de algodão colorido, com novas experiências em campo e formas de armazenamento que outros testes sejam realizados e novos resultados sejam alcançados e difundidos.

\section{Conflito de interesses}

Os autores declaram não haver conflito de interesses.

\section{Referências}

Almeida, J. N. A produção do algodão agroecológico no Projeto de Assentamento Queimadas, Remígio/PB. Campina Grande: Universidade Estadual da Paraíba, 2011. (Monografia de graduação).

Brasil. Ministério da Agricultura, Pecuária e Abastecimento. Regras para análise de sementes. Brasília: MAPA/ACS, 2009.

Brunetta, P. S. F. Produção de sementes de algodão. In: Freire, E. C. (Ed.). Algodão no Cerrado do Brasil. 1. ed. Aparecida de Goiânia: Talento, 2007.

Carvalho, N. M.; Nakagawa, J. Sementes: ciência, tecnologia e produção. 4. ed. Jaboticabal: FUNEP, 2012.

Chagas, J. T. B.; Farias, J. E. C.; Souza, R. F.; Freitas Júnior, S. P. Costa, M. G. S. Germinação e vigor de sementes crioulas de feijão-caupi. Agrarian Academy, v. 5, n. 9, p. 487-498, 2018.

Cocco, L. D. Desempenho fisiológico de sementes de algodão. Pelotas: Universidade Federal de Pelotas, 2012. (Dissertação de mestrado profissionalizante).

EMBRAPA - Empresa Brasileira de Pesquisa Agropecuária. Nordeste: Cultivar de Algodão Colorido BRS 200 Marrom. In: Silva, H. D. A EMBRAPA e a agricultura familiar. Brasília: EMBRAPA, 2002.

Fernandes, A.; Oliveira, H. M.; Pinheiro, M.; Mastroianni, R.; Lima, P. J. B. F.; Senna, T. S. Curso sobre consórcios agroecológicos. Fortaleza: ESPLAR, 2004.

Freire, E. C. Algodão colorido. Biotecnologia, Ciência e Desenvolvimento, v. 1, n. 1, p. 1-4, 2018.

Fuzatto, M. G.; Carvalho, L. H.; Cia, E.; Silva, N. M.; Chiavegato, E. J.; Lüders, R. R. Algodão (Gossypium hirsutum L.). 7. ed. Campinas: Instituto Agronômico, 2014. (Boletim IAC, no 200).

Globo. Empresa lança jeans produzido com algodão colorido da Paraíba. G1 globo.com. Paraíba, 12 de novembro de 2019. Disponível em: <https://g1.globo.com/pb/paraiba/noticia/2019/11/12/empresa-lanca-jeansproduzido-com-algodao-colorido-da-paraiba.ghtml>. Acesso em: 20 dez. 2019.

Lopes, K. P., Bruno, R. L. A.; Costa, R. F.; Bruno, G. B.; Rocha, M. S. Efeito do beneficiamento na qualidade fisiológica e sanitária de sementes do algodoeiro herbáceo. Revista Brasileira de Engenharia Agrícola e Ambiental, v. 10, n. 2, p. 426-435, 2006. https://doi.org/10.1590/S1415-43662006000200025 
Marcos Filho, J. Fisiologia de sementes de plantas cultivadas. Piracicaba: FEALQ, 2005.

Moraes, S. A. Amendoim: principais doenças, manejo integrado e recomendações de controle. 2006. Disponível em: <http://www.infobibos.com/Artigos/2006_2/Amendoim/ index.htm>. Acesso em: 21 dez. 2020.

Moura, F. T.; Silva, S. C. Algodão colorido: um produto desenvolvido para preservar o meio ambiente e gerar renda para o agricultor familiar. Campina Grande: EMBRAPA Algodão, 2014.

Nunes, R. T. C.; Prado, T. R.; Ribeiro, E. B.; Vale, W. S.; Morais, O. M. Desempenho fisiológico de sementes de algodão cultivadas em Luís Eduardo Magalhães, Bahia. Revista Verde de Agroecologia e Desenvolvimento Sustentável, v. 10, n. 4, p.69-74, 2015. https://doi.org/10.18378/rvads.v10i4.3549

Nunes, S. P. L. Teste de classificação de plântulas normais fortes para as espécies Enterolobium contortisiliquum, Pityrocarpa moniliformis e Poincianella pyramidalis. Macaíba: Universidade Federal do Rio Grande do Norte, 2018. (Monografia de graduação).

Oliveira, A. S.; Carvalho, M. L. M.; Bárbara, C. N. V.; Silva, H. P.; Neves, J. M. G. Alterações no potencial fisiológico de sementes de algodão armazenadas em diferentes ambientes. Anais do IV Congresso Brasileiro de Mamona e I Simpósio Internacional de Oleaginosas Energéticas, João Pessoa, Embrapa Algodão, p. 1939-1943, 2010.

Queiroga, V. P.; Castro, L. B. Q. C.; Gouveia, J. P. G. G. Efeito do grau de umidade inicial das sementes de algodão sobre a qualidade fisiológica durante o armazenamento. Anais do VII Congresso Brasileiro do Algodão, Foz do Iguaçu, Embrapa Algodão, p. 1823-1828, 2009.

Thomazini, A.; Martins, L. D. Qualidade física e fisiológica de sementes de girassol (Helianthus annuus L.) cultivar MG2 em condições de casa de vegetação e laboratório. Enciclopédia Biosfera, v. 7, n. 12 p. 1-9, 2011.

Informação da Licença: Este é um artigo Open Access distribuído sob os termos da Licença Creative Commons Attribution, que permite uso irrestrito, distribuição e reprodução em qualquer meio, desde que a obra original seja devidamente citada. 